\title{
Automatic Vaccum Recording Controller of Furnace Chamber*
}

\author{
Tadao Tomonari**, Masao TAKAhashi**, Senichi TogawA** and Hideo ArakawA**
}

An apparatus for the recording and controlling of pressure in furnace chambers which is indispensable in studiyings high-temperature chemistry is taken up in this paper. As shown in the block diagram of Fig. 1, the pressure in furnace chamber (F) was transformed into two kinds of electromotive

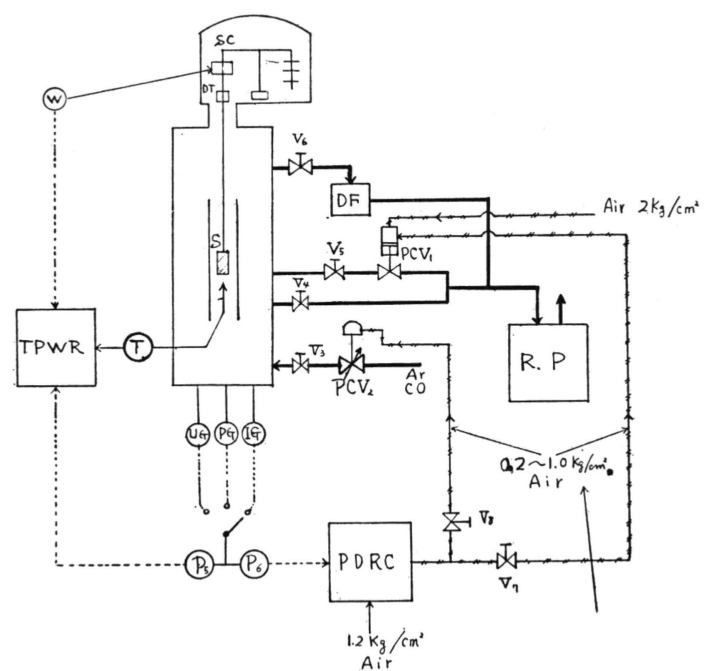

Fig. 1 Block diagram of automatic pressure control device.

force, $0 \sim 5 \mathrm{mV}\left(\mathrm{P}_{5}\right)$ and $0 \sim 10 \mathrm{mV}\left(\mathrm{P}_{10}\right)$, by a mercury manometer (UG) in the range of $250 \sim 0.5 \mathrm{mmHg}$, Pirani gauge $(\mathrm{PG})$ in $5 \times 10^{-1} \sim 10^{-3} \mathrm{mmHg}$ and ionization gauge (IG) in $10^{-3} \sim 10^{-6} \mathrm{mmHg}$, respectively. When the mercury manometer was used to transmit electromotive force in response to its mercury level, the Pirani and the ionization gauges were stabilized against the variation of line source. One of the electric outputs of the above-mentioned vacuum gauges $5 \mathrm{mV}$ full scale $\left(\mathrm{P}_{5}\right)$ was recorded by a threepoint type electronic recording potentiometer (TPWR) of $5 \mathrm{mV}$ in full scale, of $3 \mathrm{sec}$. of pen speed and of $7.5 \mathrm{sec}$. in recording interval, by which the temperature of a specimen transformed by a pyrometer (T) and its weight transformed by an automatic balance (W) were also recorded simultaneously. The furnace chamber was cleared by a rotary pump (RP) with pumping speed of $2,000 \mathrm{l} / \mathrm{min}$. and an oil diffusion pump (DF) with pumping speed of $1,500 \mathrm{l} / \mathrm{sec}$ as has already been described in details in the first report. The electric output of $10 \mathrm{mV}\left(\mathrm{P}_{10}\right)$ was connected to the deviation recording pneumatic controller (PDRC) of $10 \mathrm{mV}$ in full scale and of proportional, reset and rate actions. By this controller, the deviation between recorded pressure and setting value was detected and the controlling pressure of $0.2 \sim 1.0 \mathrm{~kg} / \mathrm{cm}^{2}$ was transmitted so as to diminish this deviation. The pressure control of the furnace chamber in the range of $250 \sim 10^{-2} \mathrm{mmHg}$ was performed by regulating the conductance of evacuating pipe line of the rotary pump by the action of control valve $\left(\mathrm{PCV}_{1}\right)$. As shown in Fig. 2, this valve is provided with a parabolic-type plug, which is shifted up and down by the action of pneumatic actuator. The actuator was a kind of springless-type piston air motor and both actuating air $\left(2 \mathrm{~kg} / \mathrm{cm}^{2}\right)$ and controlling air $\left(0.2 \sim 1.0 \mathrm{~kg} / \mathrm{cm}^{2}\right)$ were fad. The piston always took the posi-

* On the Fundamental Study of High-Temperature Chemistry (Part 4).

** Department of Electrochemistry and Institute of Carbide Chemistry, Yokohama National University, Yokohama. The original written in Japanese can be seen in J. Electrochem. Soc. Japan, 26, 564 (1958). 


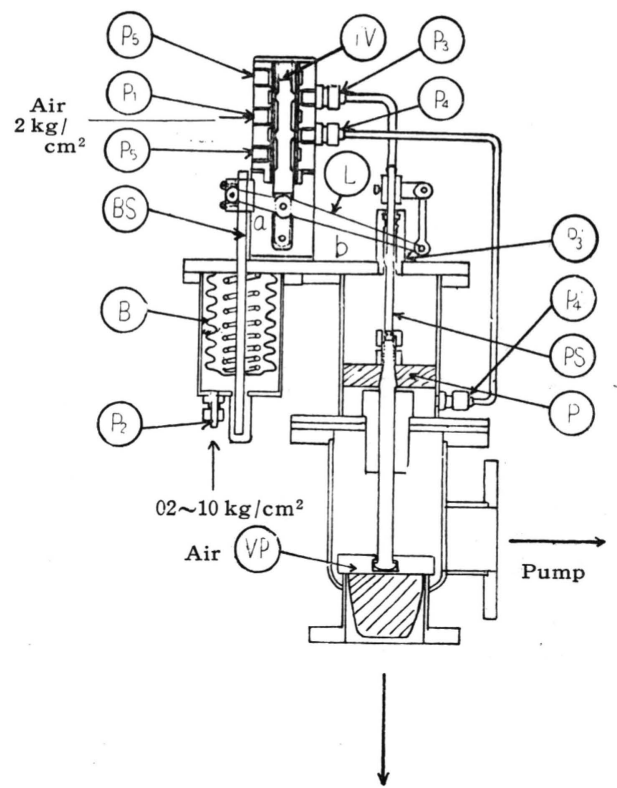

Farnace Chamber

$\begin{array}{ll}\mathrm{P}_{1}: \text { Actuating air inlet } & \mathrm{PS}: \text { Piston rod } \\ \mathrm{P}_{2}: \text { Controlling air inlet } & \mathrm{TV}: \text { Thrust value } \\ \mathrm{P}_{3}: \text { Actuating air outlet } & \mathrm{L}: \text { Lever } \\ \mathrm{P}_{4}: \text { Actuating air outlet } & \mathrm{BS}: \text { Bellows } \\ \mathrm{P}_{3} \text { : Actuating air inlet } & \mathrm{P}: \text { Piston } \\ \mathrm{P}_{4}{ }^{\prime}: \text { Actuating air inlet } & \mathrm{VP}: \text { Value plug }\end{array}$

Fig. 2 Sectional elevation of automatic value.

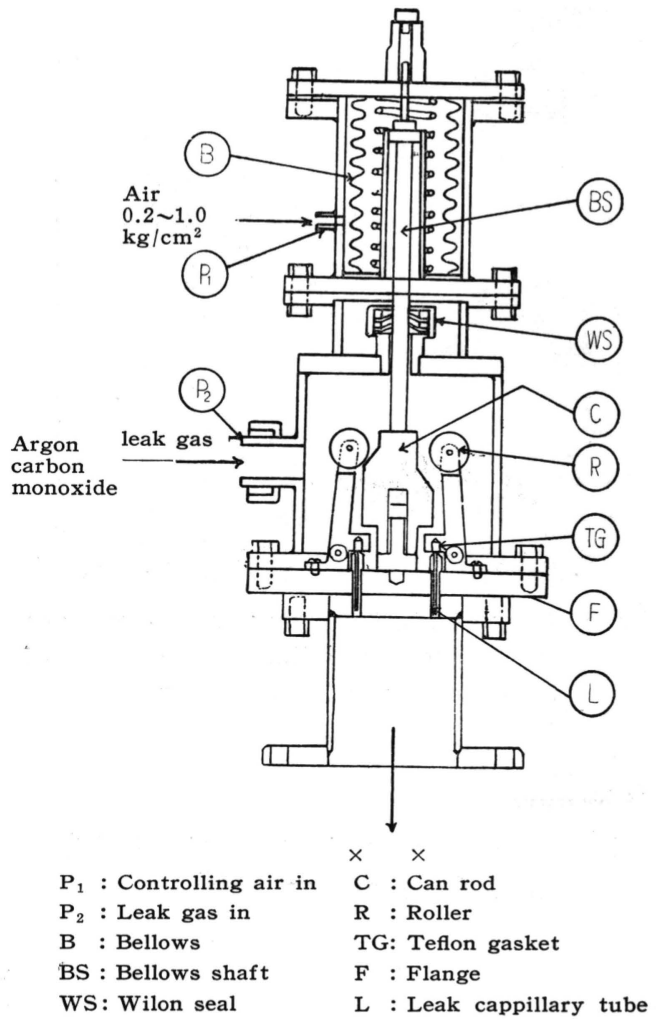

Fig. 3 Automatic leak value.

tion of responding to the controlling pressure and consequently the valve-opening was set at the pump corresponding to the signal from the controller. The control in range of $10^{-3} \sim 10^{-4} \mathrm{mmHg}$ was performed by automatic variable leak valve $\left(\mathrm{PCV}_{2}\right)$ and evacuated by the oil diffusion pump. This valve, as shown in Fig. 3, was provided with 12 capillary tubes as leak element and pneumatic actuator to shut and open these leak tubes. Figs. 4 7 show four sections from a recording chart indicating the performances of these controlling devices. Good results were obtained.

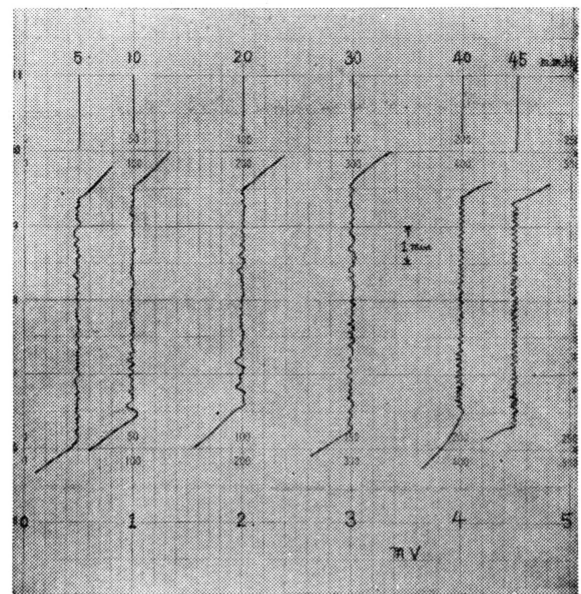

Fig. 4 Recorder chart showing the performance of pressure controller in the range of $5 \mathrm{mmHg}$ to $45 \mathrm{mmHg}$.

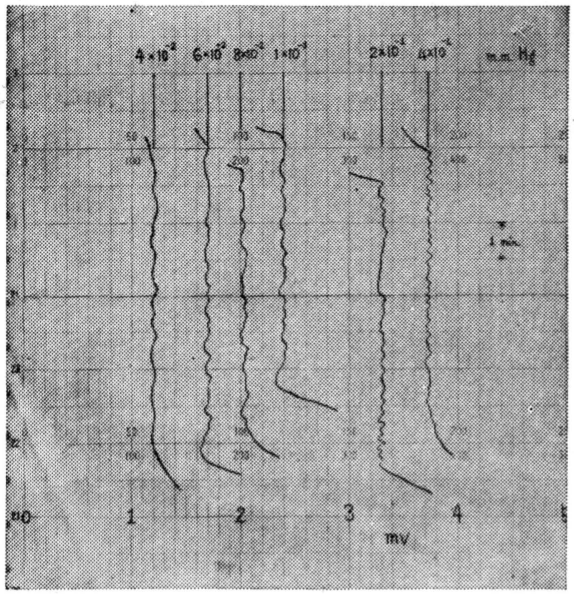

Fig. 5 Recorder chart showing the performance of pressure controller in the range of $4 \times 10^{-2} \mathrm{mmHg}$ to $4 \times 10^{-1} \mathrm{mmHg}$. 


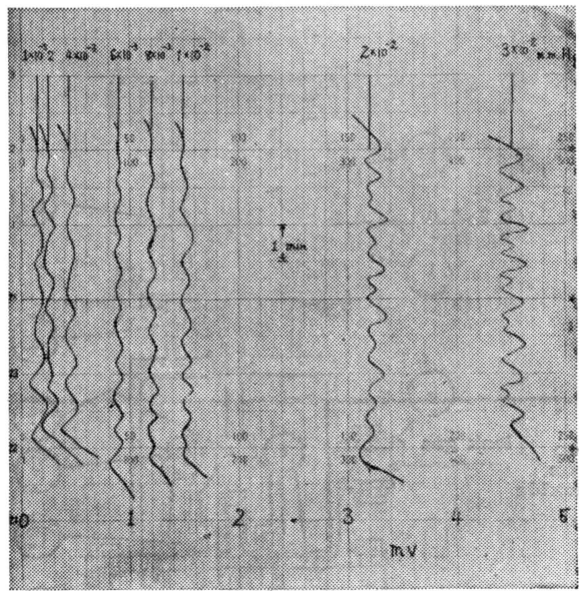

Fig. 6 Recorder chart showing the performance of pressure controller in the range of $1 \times 10^{-3} \mathrm{mmHg}$ to $3 \times 10^{-2} \mathrm{mmHg}$.

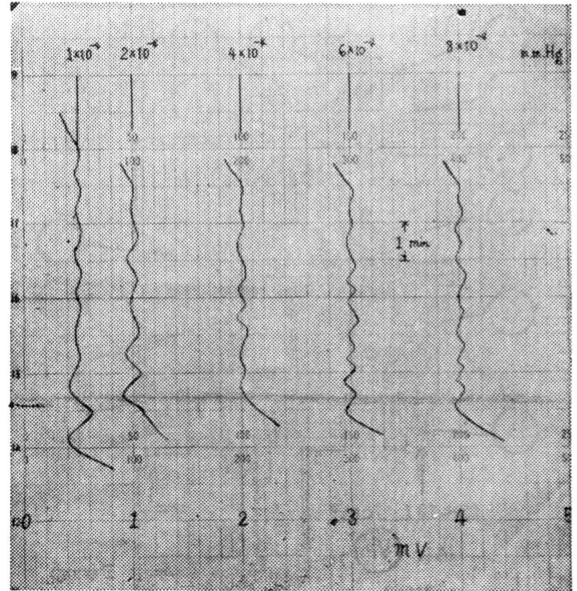

Fig. 7 Recorder chart showing the performance of pressure controller in the range of $1 \times 10^{-4}$ to $8 \times 10^{-4} \mathrm{mmHg}$.

(Received July 11, 1958)

\section{Literature :}

(1) Tadao Tomonari, Masao Takahashi, Sen-ichi Togawa, Hideo Arakawa : J. Electrochem. Soc. Japan. 25, 475 (1957) 